\title{
Responses of photosynthesis and stomatal conductance to atmospheric humidity in some mediterranean Abies species
}

\author{
J.M. Guehl' ${ }^{1}$, J. Bouachrine ${ }^{1}$, R. Zimmermann ${ }^{2}$ and E. Dreyer ${ }^{1}$ \\ 1 Laboratoire de Bioclimatologie-Ecophysiologie Forestière, Station de Sylviculture et Production, \\ INRA, Centre de Nancy, F-54280 Seichamps, France, and \\ 2Lehrstuhl für Pfanzenökologie, Universität Bayreuth, Postfach 3008, D-8580 Bayreuth, F.R.G.
}

\section{Introduction}

Leaf gas-exchange has long been shown to be sensitive to changes in the water vapor mole fraction difference between the leaf and the air $(\Delta w)$ (Sandford and Jarvis, 1986; Schulze, 1986). It has been proposed (Guehl and Aussenac, 1987; Grieu et al., 1988) that decreasing $\mathrm{CO}_{2}$ assimilation in response to increasing $\Delta w$ is not only due to stomatal closure, but could be, at least partially, a consequence of altered mesophyll photosynthetic capacity. However, that interpretation is not consensual (Terashima et al., 1988). We report herein results providing further evidence for the existence of a mesophyll effect in response to increasing $\Delta w$ in some mediterranean Abies species. The study was also aimed at determining whether the different species examined exhibit differences in their water use efficiencies.

\section{Materials and Methods}

Responses of $\mathrm{CO}_{2}$ assimilation rate $(A)$ and transpiration rate $(E)$ to varying $\Delta w$ were as- sessed under controlled environmental conditions with an open gas-exchange measurement system on intact or excised shoots of different mediterranean coniferous species. Stomatal conductance $\left(g_{S}\right)$ and intercellular $\mathrm{CO}_{2}$ concentration $\left(C_{i}\right)$ were calculated from the gasexchange data using classical equations (see Guehl and Aussenac, 1987). Prior to $\Delta w$ being increased, the short-term response of gasexchange to increasing ambient $\mathrm{CO}_{2}$ concentration $\left(C_{a}\right)$ was assessed, and the corresponding $A\left(C_{i}\right)$ functions were determined, thus allowing the analysis of $\mathrm{CO}_{2}$ assimilation in terms of mesophyll photosynthetic capacity (demand function, see Fig. 1) and diffusional limitation of $\mathrm{CO}_{2}$ supply to the chloroplasts (supply function). The $A\left(C_{j}\right)$ functions were also used to determine the marginal water cost of $\mathrm{CO}_{2}$ assimilation $(\partial E / \partial A$ ) (Guehl and Aussenac, 1987) and to examine the gas-exchange regulation with respect to the optimization theory of Cowan and Farquhar (1977).

\section{Results and Discussion}

Increasing $\Delta w$ resulted in markedly lowered $A$ (Fig. 1a) and $g_{S}$ (Fig. 1b) in seedlings of Abies nordmanniana. Stomatal closure was efficient enough for the $E(\Delta w)$ response to exhibit a maximum at 


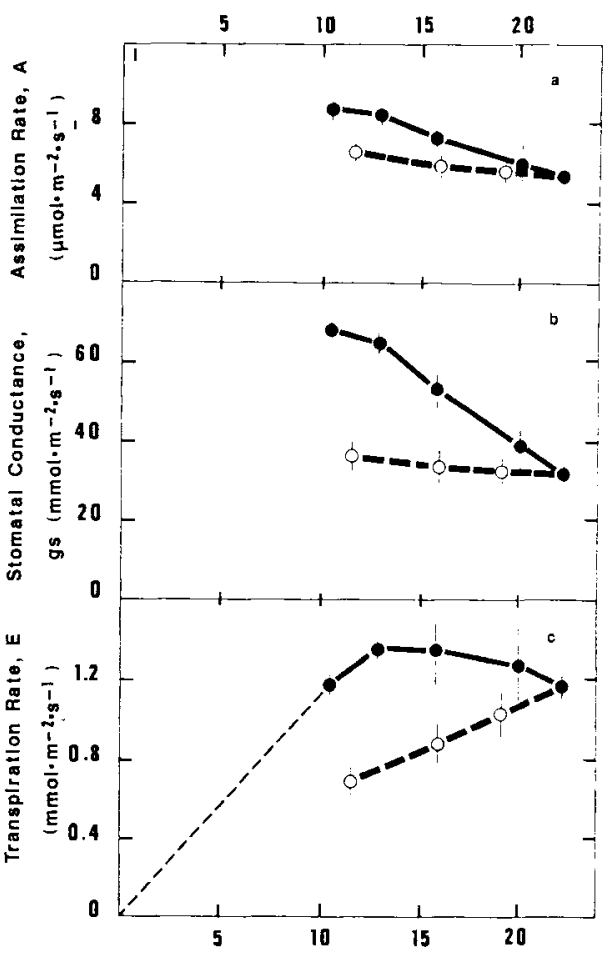

Leaf - air Mole Fraction Difference, $\Delta w$ $\left(\mathbf{P a}-\mathrm{KPa}^{-1}\right)$

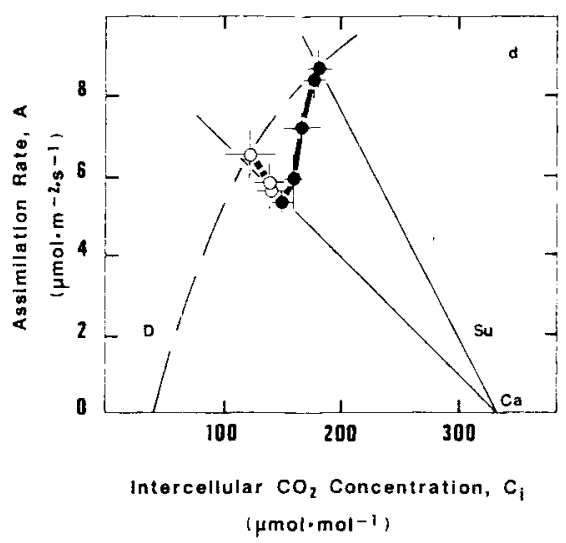

Fig. 1. Gas-exchange response (a, b, c) and $\mathrm{CO}_{2}$ assimilation rate vs calculated intercellular $\mathrm{CO}_{2}$ concentration (d) as leaf-to-air water vapor mole fraction difference was increased stepwise (closed symbols) and then returned (open symbols) near its initial level in 3 yr old $A$. nordmanniana seedlings. Bars are \pm $1 \mathrm{SEM}, n=4$. $D$ : demand function; $S u$ : supply function; $C_{2}$ ambient $\mathrm{CO}_{2}$ concentration. Air temperature, $22.0 \pm 0.5^{\circ} \mathrm{C}$, incident photosynthetic photon flux density, $500 \mu \mathrm{mol} \cdot \mathrm{m}^{-2} \cdot \mathrm{s}^{-1}$.

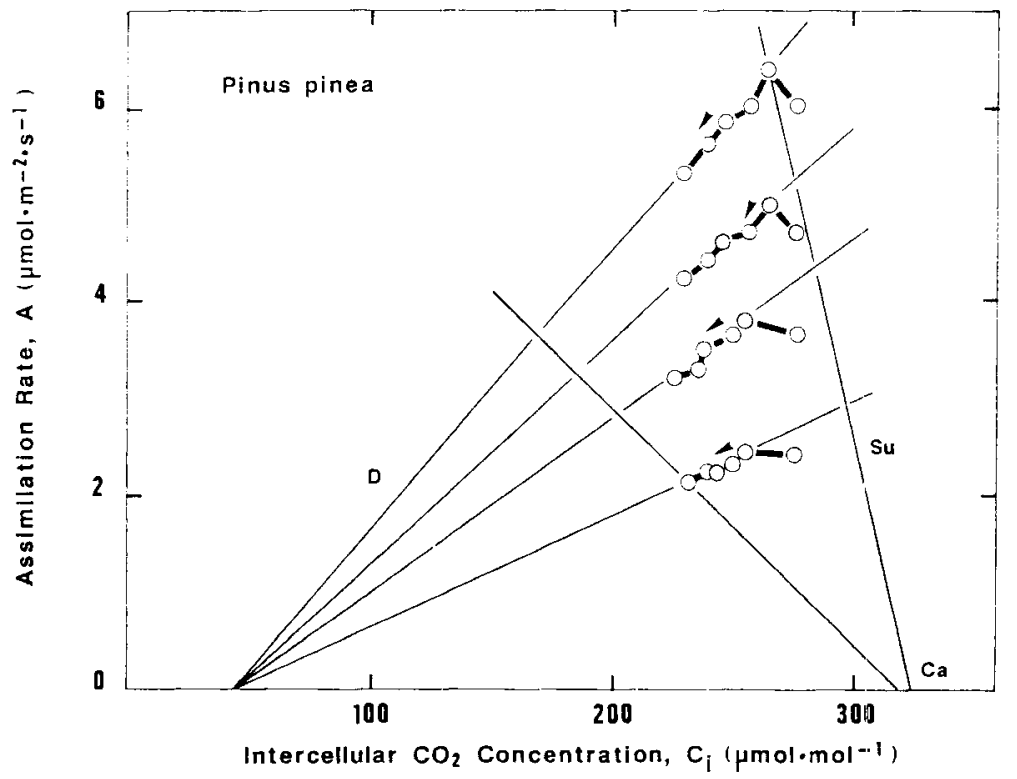

Fig. 2. Carbon dioxide assimilation rate versus intercellular $\mathrm{CO}_{2}$ concentration as leafto-air water vapor mole fraction difference was increased stepwise from 7.0 to 22.0 $\mathrm{Pa} \cdot \mathrm{kPa}^{-1}$ in $4,1 \mathrm{yr}$ old $P$. pinea seed. lings. Arrowheads indicate increas. ing $\Delta w$. $D$ : demand function; Su: supply function; $C_{a}$. ambient $\mathrm{CO}_{2}$ concentration. Air temperature, $22.0 \pm$ $0.5^{\circ} \mathrm{C}$, incident photosynthetic photon flux density, $500 \mu \mathrm{mol}$. $\mathrm{m}^{-2} \cdot \mathrm{s}^{-1}$. 


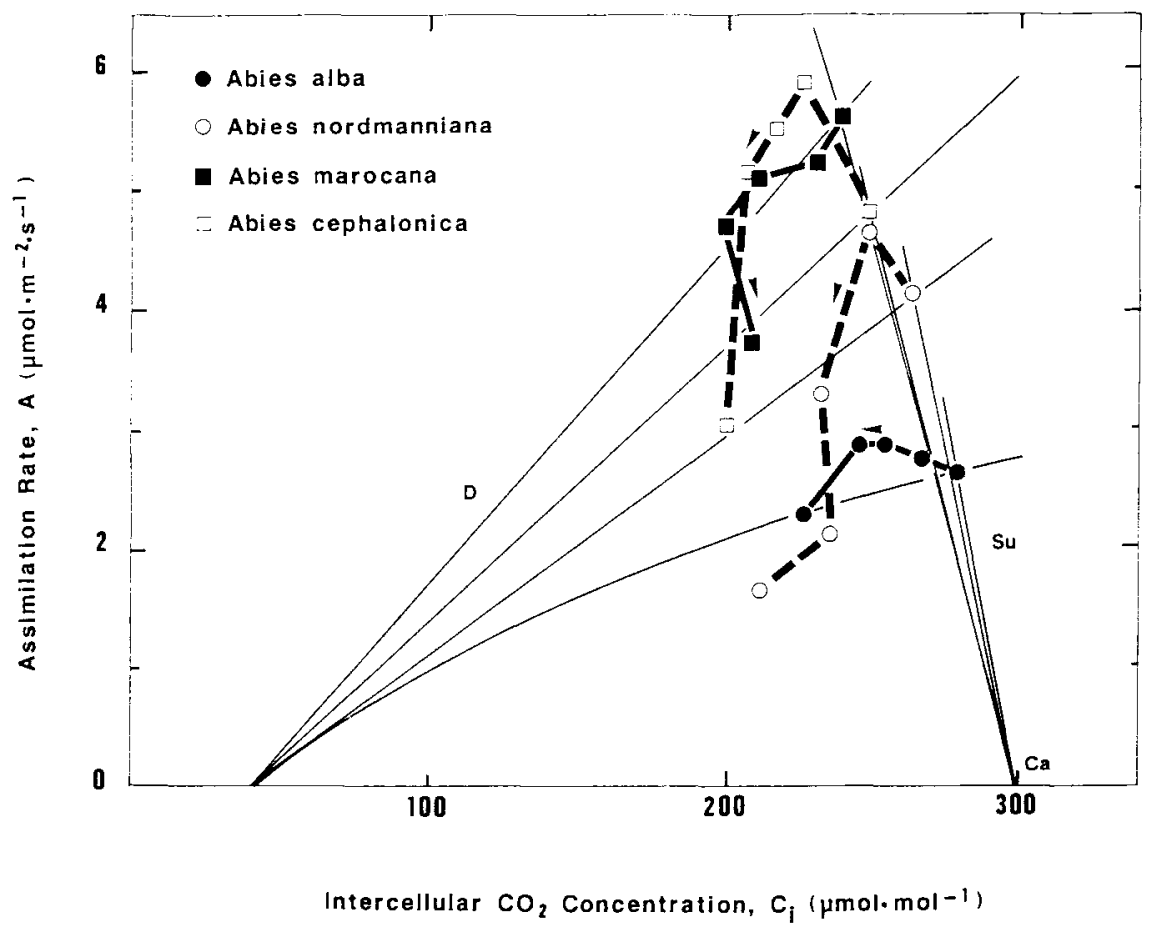

Fig. 3. Carbon dioxide assimilation rate versus calculated intercellular $\mathrm{CO}_{2}$ concentration as leaf-to-air vapor mole

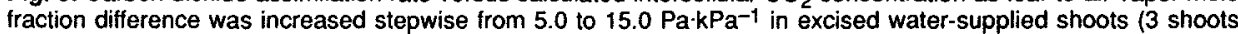
from different trees for each species) harvested from $25 \mathrm{yr}$ old stands of 4 Abies species. Arrowheads indicate increasing $\Delta w$. For each species, demand $(D)$ and supply $(S u)$ functions are represented for the point of lowest $\Delta w$. $C_{a}$ : ambient $\mathrm{CO}_{2}$ concentration. Air temperature, $22.0 \pm 0.5^{\circ} \mathrm{C}$, incident photosynthetic photon flux density, $460 \mu \mathrm{mol} \cdot \mathrm{m}^{-2} \cdot \mathrm{s}^{-1}$.

about $\Delta w=12 \mathrm{~Pa}^{-\mathrm{kPa}^{-1}}$ (Fig. 1c), thus supporting the postulate (Schulze, 1986) that alterations of leaf water status are not involved in the responses of $A$ and $g_{S}$ to $\Delta w$. Analyzing the data in an $A$ vs $C_{i}$ graph (Fig. 1d, closed symbols) showed, as had already been found for other coniferous species (Guehl and Aussenac, 1987; Grieu et al., 1988), that the experimental points did not remain on the initial demand function. That such a reponse pattern actually denotes an effect of $\Delta w$ on the mesophyll photosynthetic capacity, and is not an artifact due to improper $C_{i}$ calcula- tion (Terashima et al., 1988), was shown in the second phase of the experiment in which $\Delta w$ was returned near its initial low level. During that phase, $A$ recovered partially, with the data points remaining approximately on the same supply function (Fig. 1d, open symbols), thus indicating that the recovery of $A$ was almost fully accounted for by a recovery of mesophyll photosynthesis. Fig. 2 gives a further example of uncoupling between diffusional and mesophyll photosynthetic processes in response to increasing $\Delta w$ : Pinus pinea seedlings, having a leaf diffusional struc- 


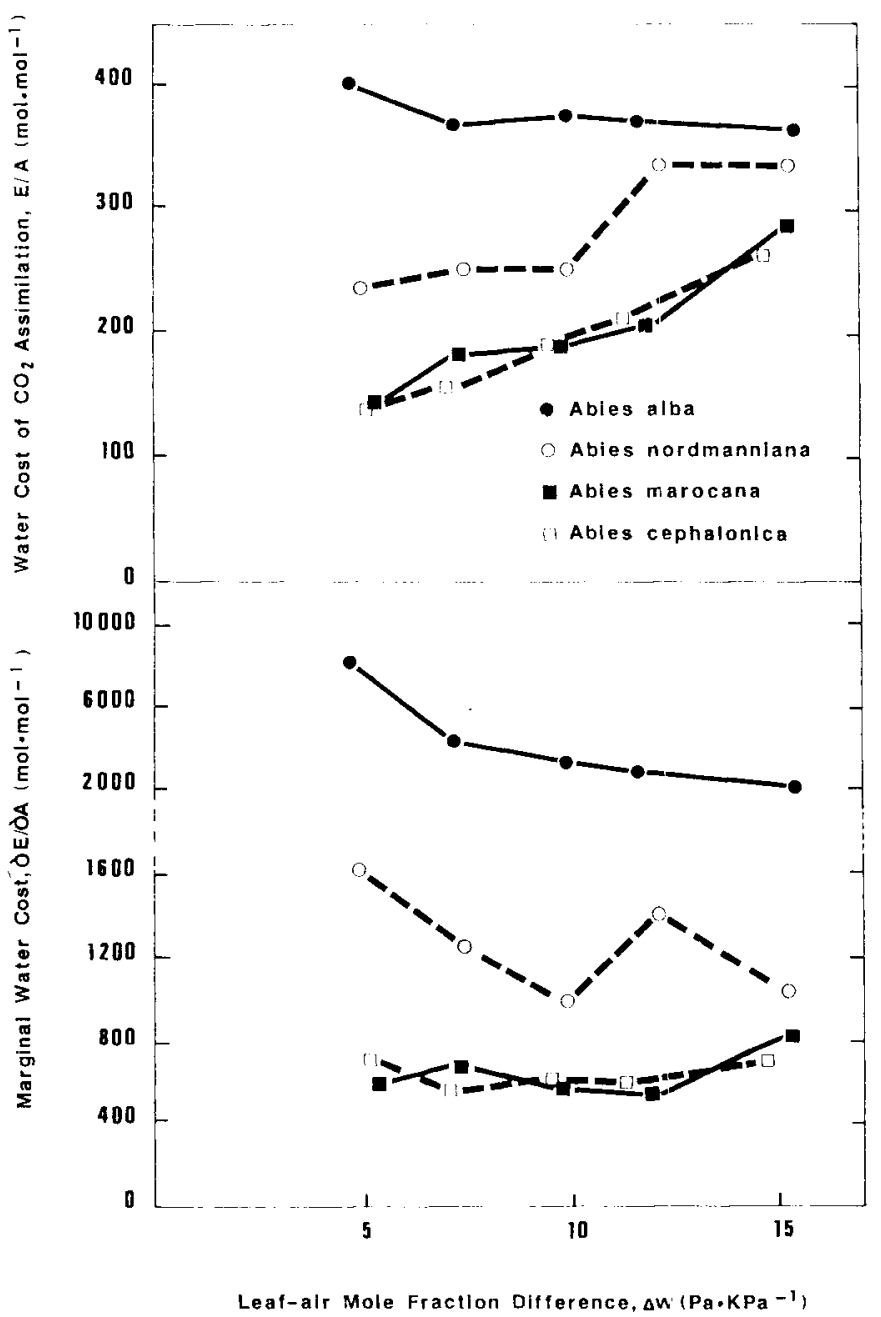

Fig. 4. The effect of increasing leaf-to-air water vapor mole fraction difference on water cost and marginal water cost $\mathrm{CO}_{2}$ assimilation in 4 Abies species. Same data as in Fig. 3.

ture not fundamentally different from that of the Abies exhibited a pure stomatal response (constant $D$ function) of $A$ to $\Delta w$ between 10.0 and 22.0 $\mathrm{Pa}^{\mathrm{kPa}} \mathrm{Pa}^{-1}$.

Significant differences in the gasexchange response to $\Delta w$ (Fig. 3) were found in a comparative study on 4 Abies species originating from different high ele- vation regions of the Mediterranean area. $A$. cephalonica and $A$. marocana had the highest $A$ values for a given $\Delta w$. These 2 species had also the lowest $E / A$ and $\partial E / \partial A$ ratios (Fig. 4) and, furthermore, $\partial E / \partial A$ was constant with $\Delta w$, which indicates optimization between $\mathrm{CO}_{2}$ assimilation and transpirational water losses 
(Cowan and Farquhar, 1977). In A. nordmanniana and $A$. alba, $E / A$ and $\partial E / \partial A$ were higher and optimization was not achieved. These results are in good agreement with the growth performances of the studied species in southern France.

\section{References}

Cowan I.R. \& Farquhar G.D. (1977) Stomatal function in relation to leaf metabolism and environment. Symp. Soc. Exp. Biol. 31, 471-505

Grieu P., Guehl J.M. \& Aussenac G. (1988) The effects of soil and atmospheric drought on photosynthesis and stomatal control of gas ex- change in three coniferous species. Physiol. Plant. 73, 97-104

Guehl J.M. \& Aussenac G. (1987) Photosynthesis decrease and stomatal control of gas exchange in Abies alba Mill. in response to vapor pressure difference. Plant Physiol. 83, 316-322

Sandford A.P. \& Jarvis P.G. (1986) Stomatal responses to humidity in selected conifers. Tree Physiol. 2, 89-103

Schulze E.D. (1986) Carbon dioxide and water vapor exchange in response to drought in the atmosphere and in the soil. Annu. Rev. Plant Physiol. 37, 247-274

Terashima I., Wong S.C., Osmond C.B. \& Farquhar G.D. (1988) Characterization of non-uniform photosynthesis induced by abscisic acid in leaves having different mesophyll anatomies. Plant Cell Physiol. 29, 385-394 